\title{
Abordagens para a temática ambiental em cursos de licenciatura em Física
}

\section{Approaches to environmental issues in Physics teacher education programs}

Danielle Aparecida Reis Leite ${ }^{1}$

Luciano Fernandes Silva²

1Universidade Federal do Triângulo Mineiro (UFTM), Departamento de Educação em Ciências, Matemática e
Tecnologias, Uberaba, MG, Brasil.Brasil. Autora correspondente: danielle.reis@uftm.edu.br
${ }^{2}$ Universidade Federal de Itajubá (UNIFEI), Instituto de Física e Química, Itajubá, MG, Brasil.

Resumo: Neste trabalho objetivamos investigar as possibilidades para a abordagem da temática ambiental em cursos de licenciatura em Física. Para tanto, inspirados pelos procedimentos da Análise de Conteúdo, analisamos os projetos pedagógicos de quinze cursos de licenciatura em Física oferecidos por instituições públicas de ensino superior localizadas no estado de São Paulo. Nesta análise selecionamos 70 disciplinas obrigatórias e 8 optativas, que foram organizadas em dois grupos: um que explora a inserção da temática ambiental na educação básica e visa preparar o professor para a abordagem do tema em aulas de Física, outro que analisa e descreve o meio ambiente, os fenômenos naturais e os impactos ambientais causados pelo desenvolvimento tecnológico. Todos os cursos analisados possuem, ao menos, uma disciplina que aborda aspectos da temática ambiental e, por proporem abordagens diversificadas, destacamos diferentes possibilidades para o tratamento do tema na formação inicial de professores de Física.

Palavras-chave: Ensino de física; Ensino superior; Meio ambiente; Formação inicial de professores; Projeto pedagógico.

\begin{abstract}
In this study we aim to investigate the possibilities for approaching environmental issues in Physics Teacher Education programs. Inspired by Content Analysis procedures, we analyzed the curricula of 15 Physics Teacher Education programs, offered by public Higher Education Institutions in the state of São Paulo, Brazil. In this analysis, we selected 70 required and 8 elective courses, organized into a set that explores the insertion of environmental issues in elementary education and aims to prepare the teacher to approach the topic in physics classes; and another set of courses that analyze and describe the environment, natural phenomena and environmental impacts caused by technological development. All analyzed programs have at least one course that addresses aspects of the environmental issues and, because they propose diverse approaches, we highlight different possibilities dealing with the topic in the Physics Teacher Education.

Keywords: Physics teaching; High education; Environmental issues; Initial teacher training; Curricula.
\end{abstract}

Recebido em: 19/11/2020

Aprovado em: 15/04/2021 


\section{Introdução}

Vivenciamos na atualidade uma série de problemas que estão direta ou indiretamente relacionados ao modo como historicamente nos organizamos em sociedade. Como exemplo, mencionamos a ciência e a tecnologia, que são valorizadas por conta dos incontáveis benefícios relacionados com seus produtos e aplicações. Todavia, ao mesmo tempo, os problemas sociais e ambientais ocasionados por esses mesmos produtos são cada vez mais complexos. Se, por um lado, os benefícios advindos da ciência e da tecnologia são distribuídos para uma parte restrita da sociedade, por outro, os problemas provenientes desses produtos são democraticamente compartilhados com toda a sociedade, sendo que os efeitos mais prejudiciais recaem sobre a parcela mais pobre da população. Esse cenário requer dos cidadãos a capacidade de realizar uma leitura crítica dessa conjuntura, a fim de que os impasses cotidianos, resultantes desse contexto complexo, possam ser enfrentados (REIS; SILVA; FIGUEIREDO, 2015; SILVA; CARVALHO, 2019; WATANABE, 2012).

Tendo em vista essas circunstâncias, o ambiente escolar é apresentado como um dos espaços privilegiados para a formação de pessoas capacitadas para o enfrentamento de diferentes problemas, dos quais destacamos os ambientais (CARVALHO, 2006). Nesse contexto, e também partindo da compreensão que a alfabetização científica e tecnológica dos cidadãos é fundamental para a superação desses desafios, consideramos as contribuições advindas da área da Educação em Ciências como essenciais para a formação de sujeitos capacitados para agirem criticamente diante dos impactos da atividade antropogênica no meio ambiente.

De acordo com Silva e Carvalho (2019), a área de Educação em Ciências tem sido responsável por produzir uma série de investigações centradas na temática ambiental. Os autores destacam que essas pesquisas apresentam uma "pluralidade de possibilidades" para a abordagem das questões ambientais no espaço escolar que vislumbram uma formação cidadã. Todavia, essas investigações apresentam estratégias didáticas diversificadas que são acompanhadas de variadas concepções sobre a ideia de cidadania.

De forma particular, destacamos que a abordagem da questão ambiental na educação básica não deve estar associada apenas às áreas do conhecimento que, usualmente, são relacionadas ao meio ambiente. O trabalho pedagógico com o ensino de Física, através de temas ambientais, pode contribuir para o desenvolvimento de uma compreensão ampliada do assunto, uma vez que essa área do conhecimento oferece subsídios para o desenvolvimento de uma visão de mundo complexa, pautada na crítica e reflexão (REIS; SILVA; FIGUEIREDO, 2015; WATANABE, 2012). Visão necessária para o enfrentamento dos desafios sociais e ambientais postos no século XXI.

Pensando nesses argumentos, reconhecemos a necessidade de que os professores de Física sejam preparados para abordar a temática ambiental em suas atividades de ensino, o que, por sua vez, chama a nossa atenção para os cursos responsáveis pela formação inicial desses profissionais. Nesse caso, destacamos a pesquisa de Silva (2007) centrada em um curso de licenciatura em Física de uma universidade pública do estado de São Paulo. O autor apresenta dados que indicam que, naquele contexto, havia poucas oportunidades para os licenciandos de Física vivenciarem diferentes aspectos da temática ambiental em seu curso de formação inicial. 
A partir desse cenário, temos nos debruçado sobre alguns desafios voltados para a compatibilização entre a formação de professores de Física e as importantes demandas do século XXI, que incluem, necessariamente, a temática ambiental. Temos indagado se os cursos de formação inicial têm preparado os futuros professores de Física para atuar nesse contexto desafiador, garantindo uma formação ambiental aos futuros docentes. Assim, elencamos alguns problemas que subsidiaram o desenvolvimento desta investigação: que elementos da temática ambiental são abordados em um curso de licenciatura em Física? Que abordagens curriculares são utilizadas para o tratamento da temática ambiental no processo de formação dos futuros professores de Física?

É nesse panorama que se insere a presente pesquisa, cujo objetivo é identificar e analisar os diferentes elementos da temática ambiental explorados em cursos de licenciatura em Física a fim de investigar possíveis abordagens curriculares para o tema no processo de formação inicial de professores de Física.

\section{A temática ambiental no ensino de física: possibilidades oferecidas por algumas abordagens curriculares}

Em âmbito nacional e internacional, os discursos que tratam das aproximações entre a Educação em Ciências (EC) e a Educação Ambiental (EA) indicam a necessidade de repensar os propósitos da educação científica (PEDRETTI, 2014; ROTH; LEE, 2002; SADLER; MURAKAMI, 2014; SUND, 2016). Esses pesquisadores argumentam que os ideais da participação democrática, cidadania e justiça social - almejados pela EA dificilmente serão alcançados se promovidos por uma educação científica centrada na transmissão/aquisição de conhecimentos científicos de maneira acrítica e desconexa do contexto social.

Esse cenário impulsionou o surgimento de um amplo movimento de inovação curricular, que visa estabelecer novos objetivos para o ensino de Ciências através da sua articulação com os desafios enfrentados pela sociedade no século XXI, dentre os quais se destacam os ambientais. De maneira específica, considera-se a necessidade de ampliar o conceito de alfabetização científica e de aproximar o contexto escolar de situações significativas para os educandos, a fim de mobilizar o envolvimento coletivo dos cidadãos nos processos de tomada de decisão.

Nesse sentido, algumas propostas indicam que os currículos de Ciências da educação básica deveriam ser estruturados a partir de temas, como os ambientais. Propostas curriculares dessa natureza podem contribuir com o desenvolvimento de uma formação mais direcionada para a construção da cidadania almejada por sociedades que valorizam a diversidade cultural e a sustentabilidade social e ambiental (SILVA; CARVALHO, 2019).

Visando o estabelecimento da articulação entre a EA e a EC, Pedretti (2014) destaca duas linhas de trabalhos educativos que contribuem com a promoção desse processo de inovação curricular: O enfoque Ciência, Tecnologia e Sociedade (CTS) e as Questões Sociocientíficas (QSC).

Pedretti e Nazir (2011) enfatizam que, dentre as diferentes reflexões sobre o significado, os problemas e as possibilidades das interrelações entre ciência, tecnologia, sociedade e meio ambiente, há tendências na abordagem CTS que valorizam os princípios de justiça, equidade, reciprocidade e responsabilidade social em relação à Natureza. Santos, Carvalho e Levinson (2014) compreendem que, ao problematizar o conhecimento 
científico no contexto social com suas implicações ambientais, os currículos com ênfase CTS contemplam uma dimensão importante da EA. Para Halmenschlager (2014), Santos (1992), e Watanabe-Caramello, Strieder e Gehlen (2012), o enfoque CTS viabiliza a problematização de temas ambientais no ensino de Ciências.

Outros pesquisadores (OWENS; SADLER; ZEIDLER, 2018; SADLER; MURAKAMI, 2014) destacam as possibilidades oferecidas pelas QSC para o estabelecimento de aproximações entre a EC e a EA. De acordo com Sadler e Murakami (2014), em meio aos inúmeros assuntos que podem ser classificados como uma Questão Sociocientífica, encontram-se as questões ambientais. Considerando que as QSC são de natureza controversa, os autores enfatizam algumas possibilidades para a construção de atividades de ensino de Ciências centradas nas controvérsias da temática ambiental, o que possibilita o desenvolvimento do senso crítico por meio do incentivo à elaboração de argumentos em situações que envolvem algum tipo de impasse, promovendo discussões democráticas, que valorizam os princípios da cidadania e da justiça social.

Por fim, dentre essas perspectivas que apresentam novas maneiras de pensar e organizar as propostas curriculares e que viabilizam a abordagem de temáticas ambientais no ensino de Ciências destacamos, ainda, a Abordagem Temática (AT). Conforme é esclarecido por Delizoicov, Angotti e Pernambuco (2011, p. 189), a AT é uma "[...] perspectiva curricular cuja lógica de organização é estruturada com base em temas, através dos quais são selecionados os conteúdos de ensino das disciplinas". Nesse contexto, em oposição à Abordagem Conceitual - que estrutura o currículo de acordo com os conceitos científicos, a partir dos quais são determinados os conteúdos a serem abordados nas atividades de ensino - a AT propõe que a estrutura curricular seja organizada segundo temas significativos para a vida dos estudantes.

Por ser um tema contemporâneo relevante para a sociedade e que, em contextos particulares, possui algum tipo de significado para os estudantes, a questão ambiental atende aos requisitos propostos pela AT. Então, essa abordagem curricular viabiliza a incorporação de temáticas ambientais no currículo de Ciências, contribuindo para uma formação crítica e reflexiva (WATANABE-CARAMELLO; STRIEDER; GEHLEN, 2012).

Tendo em mente esses posicionamentos, estabelecemos um diálogo com pesquisadores que destacam as possibilidades oferecidas pelo ensino de Física para a abordagem da temática ambiental nos currículos de ciências da educação básica (REIS; SILVA; FIGUEIREDO, 2015; SILVA, 2007; STRIEDER, 2008; WATANABE, 2012). Conceitualmente, os autores enfatizam essa como uma oportunidade de ressignificar o ensino de Física, de forma a superar aquelas compreensões ainda arraigadas em um ensino puramente conceitual. Do ponto de vista metodológico, destacam propostas que visam o desenvolvimento de posicionamentos críticos e reflexivos diante dos problemas socioambientais. Tais pesquisadores apresentam um discurso alinhado às discussões mobilizadas no campo da Educação em Ciências anteriormente apresentadas.

Pensando nas considerações apontadas até o momento e que revelam alguns caminhos possíveis para a articulação entre o ensino de Física e a temática ambiental, compreendemos que essas questões devem ser valorizadas pelos cursos de licenciatura em Física. 


\section{Aspectos metodológicos}

A fim de selecionar os cursos de licenciatura em Física para a análise, inicialmente realizamos uma consulta ao site do e-MEC' (BRASIL, 2017). De acordo com as informações levantadas, até o ano de 2017 - período em que esta pesquisa estava em andamento - eram oferecidos no Brasil 238 cursos de formação inicial de professores de Física na modalidade presencial.

Para a seleção dos cursos analisados reconhecemos a pertinência de uma delimitação geográfica e, assim, optamos por analisar os cursos de formação inicial de professores de Física oferecidos por instituições de ensino superior (IES) localizadas no estado de São Paulo. Dentre outros fatores, justificam essa escolha o fato desse ser o estado que: (i) oferece o maior número de cursos de formação inicial de professores de Física no Brasil2; (ii) é um dos principais responsáveis pela produção de conhecimento na área da EA no Brasil (CARVALHO; CAVALARI; SILVA, 2015). Com isso, definimos que a investigação se ateria aos 32 cursos de formação inicial de professores de Física oferecidos por IES públicas e privadas localizadas no estado de São Paulo.

Para o levantamento dos dados escolhemos analisar os projetos pedagógicos desses cursos (PPC) e entrevistar seus coordenadores ${ }^{3}$. Em consequência, estabelecemos outros dois critérios de seleção: (i) os cursos participantes da investigação deveriam possuir, ao menos, uma turma de concluintes, uma garantia de que as diferentes oportunidades para a abordagem da temática ambiental tivessem sido vivenciadas pelos licenciandos; (ii) obter dados apenas dos cursos cujos coordenadores concordassem em fornecer a entrevista, já que, além de padronizar a fonte de dados, esses sujeitos acrescentariam informações importantes à pesquisa.

Por meio desses critérios selecionamos 15 cursos de licenciatura em Física oferecidos por seis IES públicas (estaduais e federais) localizadas no estado de São Paulo. Cabe destacar que 4 cursos ( 3 de IES públicas e 1 de IES privada) foram excluídos da investigação por ainda não possuírem uma turma de concluintes no momento do levantamento dos dados. Além disso, outros 13 cursos (8 de IES privadas e 5 de IES públicas) não foram investigados, uma vez que não obtivemos o retorno dos seus coordenadores com o aceite para participarem da pesquisa. A figura 1 resume as etapas percorridas para a seleção dos cursos investigados e o quadro 1 apresenta as instituições responsáveis pelo oferecimento dos cursos de licenciatura em Física selecionados para a investigação.

\footnotetext{
'Base de dados oficial e única de informações relativas às Intituições de Ensino Superior (IES) e cursos de graduação do Sistema Federal de Ensino brasileiro.

232 cursos, sendo: 29 de licenciatura em Física, 2 de licenciatura em Ciências Exatas com habilitação em Física e 1 de licenciatura Interdisciplinar em Química e Física.

${ }^{3}$ A pesquisa foi aprovada pelo Comitê de Ética em pesquisa com seres humanos em 17/05/2016 (Número do Parecer: 1.548.270).
} 
Figura 1 - Etapas percorridas para a seleção dos cursos de licenciatura em Física investigados
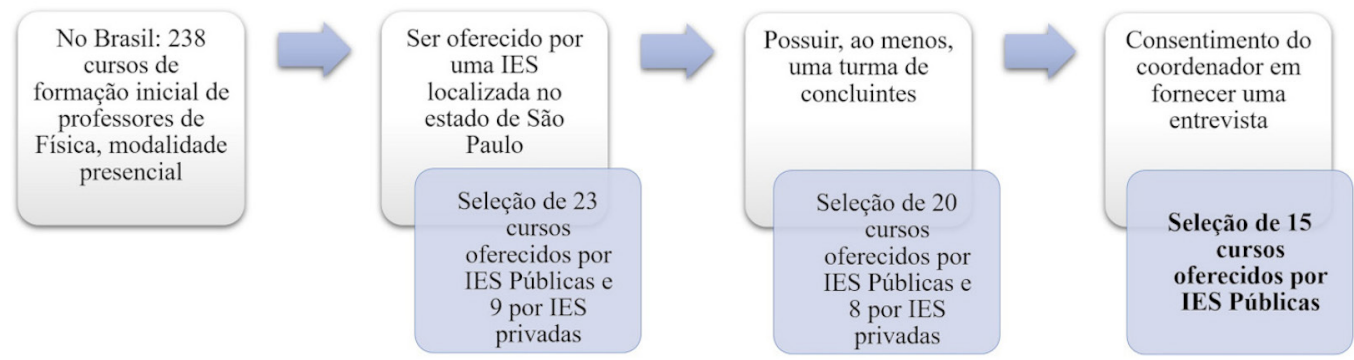

Fonte: elaborada pelos autores.

Quadro 1 - Cursos de licenciatura em Física, oferecidos por IES públicas localizadas no estado de São Paulo, selecionados para investigação

\begin{tabular}{|l|l|}
\hline \multicolumn{1}{|c|}{ Instituições de Ensino Superior (IES) } & \multicolumn{1}{c|}{ Campus } \\
\hline $\begin{array}{l}\text { Instituto Federal de Educação, Ciência e Tecnologia de São } \\
\text { Paulo }\end{array}$ & Birigui; Itapetininga; Piracicaba; São Paulo \\
\hline Universidade Estadual Paulista & Guaratinguetá; llha Solteira; Rio Claro; São José do Rio Preto \\
\hline Universidade Federal de São Carlos & Araras; São Carlos (Integral e Noturno); Sorocaba \\
\hline Universidade Federal do ABC & Santo André \\
\hline Universidade de São Paulo & São Paulo \\
\hline Universidade Estadual de Campinas & Campinas \\
\hline
\end{tabular}

Fonte: elaborado pelos autores.

Conforme já explicitado, parte dos dados desta investigação foram levantados através da pesquisa documental (ALVES-MAZZOTTI; GEWANDSZNAJDER, 2000), ou seja, dos PPC dos cursos de licenciatura em Física analisados. Os projetos pedagógicos de cada curso foram analisados em sua integridade, nos quais buscamos por indícios específicos a respeito da abordagem da temática ambiental por esses cursos. Adicionalmente, as entrevistas semiestruturadas (FRASER; GONDIM, 2004) realizadas com os coordenadores desses cursos acrescentaram dados complementares ao exposto pelos PPC. As entrevistas permitiram explorar as motivações que levaram à inclusão da temática ambiental no curso, e os fatores que dificultam tal inserção; as relações estabelecidas entre a Física e a temática ambiental; as principais atividades responsáveis por apresentar a referida temática aos discentes; os temas ambientais mais valorizados etc.

Para a análise dos dados nos inspiramos nos procedimentos da Análise de Conteúdo (AC) proposta por Bardin (2016, p. 48) que a descreve como "[...] um conjunto de técnicas de análise das comunicações visando obter por procedimentos sistemáticos e objetivos de descrição do conteúdo das mensagens". Neste trabalho, optamos pela análise temática, com a elaboração de categorias que "[...] funciona por operações de desmembramento do texto em unidades, em categorias segundo reagrupamentos analógicos" (BARDIN, 2016, p. 201).

O percurso para a análise do material foi trilhado de acordo com a nossa interpretação das diferentes etapas da Análise de Conteúdo. Dessa maneira, realizamos algumas adaptações adequadas à nossa realidade de investigação, tendo sempre em mente as questões motivadoras e os objetivos desta pesquisa. As categorias foram elaboradas através de leitura e desmembramento dos textos, momento em que selecionamos aqueles trechos que respondiam às indagações da pesquisa e 
eram pertinentes ao objetivo. Posteriormente, esses excertos foram agrupados por semelhanças e categorizados segundo suas características afins. Parte dos dados foram organizados em duas categorias denominadas a temática ambiental e o processo educativo e análise e estudo de temas ambientais, apresentadas no tópico que segue.

\section{Elementos da temática ambiental em cursos de licenciatura em física ${ }^{4}$}

Esta seção apresenta dados sistematizados a partir da análise das ementas e dos conteúdos programáticos das disciplinas dos 15 cursos de licenciatura em Física pesquisados - um total de 659 disciplinas obrigatórias e de 364 optativas. Destas, selecionamos 70 disciplinas obrigatórias e 8 optativas que abordam elementos da temática ambiental (figura 2 ).

Figura 2 - Disciplinas obrigatórias e optativas dos cursos analisados que exploram elementos da temática ambiental

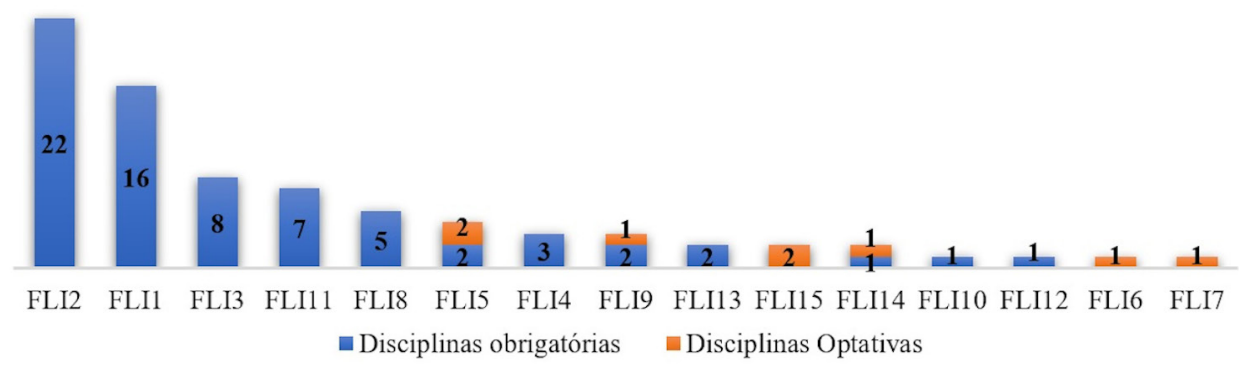

Fonte: elaborada pelos autores.

Concluímos que todos os cursos analisados possuem, ao menos, uma disciplina que explora aspectos da temática ambiental, evidenciando que os temas ambientais possuem um espaço, mesmo que pequeno, nos cursos de licenciatura em Física investigados. Outro dado interessante é que $80 \%$ desses cursos privilegiam a abordagem da temática ambiental em disciplinas obrigatórias, fazendo com que ela seja abordada, mesmo que de maneira pontual, na formação inicial do professor de Física.

Nos próximos subitens, exploramos as principais abordagens propostas para a temática ambiental nas disciplinas agrupadas em cada uma das duas categorias, evidenciando, assim, os elementos da temática ambiental abordados nesses cursos de licenciatura em Física.

\section{A temática ambiental e o processo educativo}

A primeira categoria reúne as disciplinas que tratam da inserção da temática ambiental no processo educativo e no ensino de Física, explorando: (i) o papel da educação para ressignificar a relação sociedade-Natureza; (ii) os fundamentos, diretrizes e políticas de EA; (iii) as possibilidades de abordar a temática ambiental no ensino de Física da educação básica. Esse agrupamento apresenta articulação com os campos da Educação e do Ensino de Ciências.

${ }^{4}$ Para preservar o anonimato, os cursos são nomeados pela sigla $\mathrm{FLI}_{\mathrm{n}}$ e seus respectivos coordenadores pela sigla $\mathrm{C}_{\mathrm{n}}$ - em que $\mathrm{n}$ varia de 1 a 15. 
Um conjunto de seis disciplinas (quadro 2) explora as contribuições do espaço escolar para a reconstrução da relação Sociedade-Natureza e para a formação de cidadãos comprometidos com a sustentabilidade ambiental.

Quadro 2 - Disciplinas agrupadas na subcategoria ressignificação sociedade-natureza

\begin{tabular}{|l|l|}
\hline \multicolumn{1}{|c|}{ Curso } & \multicolumn{1}{|c|}{ Disciplinas (Obrigatórias) } \\
\hline FLI $_{1}$ & Didática; Escola, Currículo e Gestão; Filosofia da Educação; Psicologia da Educação; Sociologia da Educação \\
\hline $\mathrm{FLI}_{8}$ & Sociedade, Educação e Meio Ambiente \\
\hline
\end{tabular}

Fonte: elaborado pelos autores.

Como exemplos, destacamos um dos objetivos de Filosofia da Educação, que visa "[...] Trabalhar a articulação da função social da escola para a construção de uma sociedade ambientalmente sustentável" (PPC $\mathrm{FLI}_{1}, 2017$, p. 38). E o objetivo da disciplina Sociedade, Educação e Meio Ambiente que propõe "Analisar os processos de industrialização e urbanização e seu impacto sobre o meio ambiente, suas relações sociais e manifestações culturais e a importância e o potencial da educação na transformação das relações sociais e das interações com o meio ambiente" (PPC FLI ${ }_{8^{\prime}}$ 2015, p. 68).

Recorremos a Guimarães (2017) para destacar a relevância da abordagem desse elemento da temática ambiental na formação dos professores de Física. De acordo com esse pesquisador, muitos docentes e educadores se comprometem com o propósito da construção de uma realidade socioambientalmente sustentável, todavia as suas práticas pedagógicas não condizem com este ideal. Por vezes, esses docentes reproduzem as concepções do processo educativo que, calcadas pelos paradigmas da sociedade moderna, acentuam a alienação ideológica e contribuem com a manutenção da hegemonia capitalista. Com isso, Guimarães (2017) concorda que os cursos responsáveis pela formação desses profissionais devem oferecer os subsídios necessários para o rompimento dessa visão paradigmática fragmentária, simplista e reduzida, que leva a uma compreensão limitada da problemática ambiental. Superando essas concepções reducionistas, o pesquisador concorda que esses professores terão condições de elaborar práticas educativas que favoreçam a construção de uma nova realidade socioambiental mais justa e democrática.

Com esses argumentos enfatizamos que, apesar de valorizarmos a iniciativa desses dois cursos de licenciatura em Física, essa abordagem será ainda mais significativa se promover uma reflexão crítica acerca dessa racionalidade hegemônica que impõe essa visão reducionista do meio ambiente. Por outro lado, entendemos que uma única disciplina não será a responsável para que os licenciandos construam essa nova compreensão, ou seja, o curso como um todo deve estar comprometido com esse ideal.

Considerando que essas discussões são frequentemente promovidas pelo campo da $E A$, entendemos que essa área poderá agregar contribuições importantes para a abordagem da temática ambiental nos cursos de licenciatura em Física. De fato, outra possibilidade para a abordagem de temas ambientais na formação inicial do professor de Física que identificamos nessa investigação são as disciplinas que tratam dos diferentes aspectos da educação ambiental. Um conjunto de onze disciplinas (quadro 3) explora as diretrizes, as políticas e a trajetória de institucionalização da EA, 
discute seus principais fundamentos e objetivos, traz os seus pressupostos teóricos e metodológicos, problematiza a sua inserção no espaço escolar e destaca a sua contribuição para a formação cidadã crítica.

Quadro 3 - Disciplinas agrupadas na subcategoria fundamentos, diretrizes, políticas de EA

\begin{tabular}{|l|l|}
\hline \multicolumn{1}{|c|}{ Curso } & Disciplinas (Obrigatória) \\
\hline $\mathrm{FLI}_{1}$ & História da Educação; Legislação Educacional \\
\hline $\mathrm{FLI}_{2}$ & Didática Geral; História da Educação; Políticas Públicas e organização da Educação Brasileira \\
\hline $\mathrm{FLI}_{8}$ & Educação Ambiental \\
\hline $\mathrm{FLI}_{10}$ & Fundamentos da Educação Ambiental \\
\hline $\mathrm{Curso}$ & Disciplinas (optativa ou eletiva) \\
\hline $\mathrm{FLI}_{5}$ & Educação Ambiental \\
\hline $\mathrm{FLI}_{6}$ & Ensino e Pesquisa em Educação Ambiental \\
\hline $\mathrm{FLI}_{7}$ & Ensino e Pesquisa em Educação Ambiental \\
\hline $\mathrm{FLI}_{9}$ & Educação Ambiental \\
\hline
\end{tabular}

Fonte: Elaborado pelos autores.

Entendemos que essas disciplinas são importantes para os cursos de licenciatura em Física, já que os professores em formação inicial têm a oportunidade de se aproximarem de discussões que os incentivam a repensar a problemática ambiental e a reconhecer o seu papel na inserção dessas discussões no ambiente escolar. Além disso, esses professores poderão entender que as práticas de EA na educação básica não devem se restringir a uma única disciplina ou atividade curricular, mas sim, perpassar pelos diferentes espaços de forma transversal e interdisciplinar, inclusive nas aulas de Física. Por fim, podemos dizer que ao inserir diferentes temas ambientais em suas aulas de Física, o professor poderá abordar uma dimensão importante da EA, além de buscar nesse campo elementos que enriqueçam a sua prática e as discussões que pretende promover em suas aulas.

Levando em consideração que as práticas de EA devem ser precedidas pela definição clara das perspectivas da temática ambiental e do processo educativo, a fim de firmar o comprometimento com os pressupostos e objetivos delineados (CARVALHO, 2006), trazemos mais um elemento que revela a importância de disciplinas dessa natureza em cursos de formação inicial de professores de diferentes áreas do conhecimento. Com isso, valorizamos as iniciativas de promover esse tipo de abordagem nos currículos da licenciatura em Física.

Fica evidente que as disciplinas apresentadas até aqui não exploram relações específicas com a Física ou com o ensino de Física, aproximação que está presente em um terceiro agrupamento de 22 disciplinas (quadro 4).

Quadro 4 - Disciplinas agrupadas na subcategoria abordagem da temática ambiental no ensino de Física

\begin{tabular}{|l|l|}
\hline \multicolumn{1}{|c|}{ Curso } & Disciplinas (Obrigatória) \\
\hline $\mathrm{FLI}_{1}$ & Prática Pedagógica; Prática de Ensino de Física I, II, III e IV \\
\hline $\mathrm{FLI}_{2}$ & Oficina de Projetos de Ensino de Física I, II, III e IV \\
\hline $\mathrm{FLI} 3$ & $\begin{array}{l}\text { Prática Docente I, II, III e IV; Oficina de Projetos de Ensino: Eletromagnetismo; Oficina de Projetos de Ensino: } \\
\text { Termodinâmica }\end{array}$ \\
\hline $\mathrm{FLI}_{4}$ & Física e Ciências da Terra \\
\hline $\mathrm{FLI}_{1}$ & $\begin{array}{l}\text { Estágio Supervisionado IV; Metodologia do Ensino de Física II; Instrumentação para o Ensino de Física I, II e } \\
\text { III; Questões Sociocientíficas e Argumentação }\end{array}$ \\
\hline
\end{tabular}

Fonte: elaborado pelos autores. 
Essas disciplinas oferecem os subsídios teóricos e metodológicos para que o futuro professor pense o ensino de Física na educação básica. Nesse contexto, destacam as possibilidades de que diferentes temas contemporâneos estejam presentes nas aulas de Física, dentre os quais destacam-se, frequentemente, os ambientais. Como exemplo desse tipo de abordagem, destacamos o objetivo da disciplina Prática de Ensino de Física I que "[...] prepara o futuro professor com ferramentas para atuação em sala de aula. [...] Esta disciplina discute em todas as suas abordagens as temáticas contemporâneas relacionadas: ao meio ambiente e sustentabilidade, igualdade de gênero, à inclusão social" (PPC FLI , 2017, p. 117).

Outras disciplinas desse conjunto enfocam as possibilidades para a elaboração e condução de atividades de ensino de Física centradas em temas ambientais através do enfoque CTS e das Questões Sociocientíficas. Como exemplo, citamos a disciplina Questões Sociocientíficas e Argumentação que "[...] adentra no domínio de situações em que a ciência, geralmente associada à tecnologia, gera implicações socioambientais que carrega a marca da polêmica, da controvérsia. [...] com o interesse em potencializar uma formação cidadã" (PPC $\mathrm{FLI}_{11}$, 2017, p. 15). A coordenadora desse curso destaca que a abordagem CTS é um caminho para inserir as questões ambientais na formação inicial do professor de Física:

Tanto aqui no curso quanto em eventos, eu sempre vejo a temática ambiental aparecendo dentro de uma linha de pesquisa que é Ciência, Tecnologia, Sociedade e Ambiente, a famosa CTSA [...]. É, em termos aqui do curso, nós temos sim disciplinas que puxam para essa linha temática Ciência, Tecnologia, Sociedade e Ambiente, é disciplinas específicas que hoje nós temos em nosso currículo que é uma de questões Sociocientíficas. $\left[\mathrm{C}_{11}, 2018\right]$.

Como já explorado neste trabalho, a Abordagem Temática (DELIZOICOV; ANGOTTI; PERNAMBUCO, 2011) pode viabilizar o tratamento da temática ambiental na disciplina Física. Dentre os diferentes enfoques curriculares para o tratamento de temas na sala de aula, destacamos o enfoque CTS e as QSC, principalmente por incentivarem a exploração das controvérsias e complexidades dos temas ambientais. Na medida em que incentivam o trabalho com temas sociais e ambientais relevantes, esses enfoques atribuem um novo significado para as aulas de Física. Utilizando-se dessas propostas para a abordagem da temática ambiental, o ensino de Física contribuirá com o desenvolvimento de uma visão de mundo complexa e incentivará posicionamentos críticos e reflexivos necessários para o enfrentamento dos problemas socioambientais contemporâneos.

\section{Análise e estudo de temas ambientais}

A segunda categoria agrupa as disciplinas que, com auxílio de conceitos científicos, exploram, analisam e descrevem: (i) o meio ambiente e os fenômenos naturais; (ii) os impactos ambientais causados pelo desenvolvimento tecnológico. Esse agrupamento apresenta articulação com o campo das Ciências Exatas e Naturais.

Desse grupo, 18 disciplinas (quadro 5) utilizam os conceitos das Ciências Exatas e Naturais para a análise, descrição e modelagem dos fenômenos naturais. 
Quadro 5 - Disciplinas agrupadas na subcategoria meio ambiente e fenômenos naturais

\begin{tabular}{|l|l|}
\hline \multicolumn{1}{|c|}{ Curso } & Disciplina (Obrigatória) \\
\hline $\mathrm{FLI}_{1}$ & Gravitação e Fluidos; Termodinâmica \\
\hline $\mathrm{FLI}_{2}$ & $\begin{array}{l}\text { Física Aplicada aos Fenômenos Biológicos; Fundamentos da Matemática Elementar; Fundamentos da Mecânica } \\
\text { Clássica; Fundamentos da Óptica; Fundamentos da Termodinâmica; Fundamentos do Eletromagnetismo; } \\
\text { Fundamentos dos Fenômenos Ondulatórios; Informática e Objetos de Aprendizagem }\end{array}$ \\
\hline $\mathrm{FLI}_{3}$ & Termodinâmica \\
\hline $\mathrm{FLI}_{4}$ & Física e Ciências da Vida; Termodinâmica \\
\hline $\mathrm{FLI}_{5}$ & Biodiversidade: Interações entre organismos e ambiente \\
\hline $\mathrm{FLI}_{8}$ & Introdução às Licenciaturas de Física, Química e Biologia \\
\hline $\mathrm{FLI}_{12}$ & Projetos Integradores I: Física e Sociedade \\
\hline $\mathrm{Curso}$ & Disciplina (Eletiva e Optativa) \\
\hline $\mathrm{FLI}_{5}$ & Física do meio ambiente \\
\hline $\mathrm{FLI}_{15}$ & Física do meio ambiente \\
\hline
\end{tabular}

Fonte: elaborado pelos autores.

Como exemplos, citamos a disciplina Fundamentos dos Fenômenos Ondulatórios nas Ciências Naturais e Matemática, que objetiva realizar a "[...] modelagem matemática dos fenômenos cíclicos e periódicos da Natureza" (PPC FLI, 2016, p. 84) e a disciplina Fundamentos do Eletromagnetismo que visa "[...] Compreender conceitualmente tópicos associados à Eletrostática, à Eletrodinâmica e ao Eletromagnetismo, aplicando tais conceitos aos fenômenos naturais e ambientais" (PPC $\mathrm{FLI}_{2}$, 2016, p. 132). O coordenador $\mathrm{C}_{12}$ destaca uma disciplina do curso $\mathrm{FLI}_{12}$ :

A Física é o estudo da Natureza. [...] essa disciplina, Projetos Integradores 1, envolve Física e Sociedade e engloba essa questão ambiental. Não é uma discussão muito ampla, mas é uma disciplina que engloba alguns aspectos da interação da Física e a questão do meio ambiente. [C $\left.{ }_{12}, 2017\right]$.

Essas são algumas disciplinas que exploram a temática ambiental através de uma abordagem técnico-científica por privilegiarem o estudo do meio ambiente e dos fenômenos naturais por meio de modelos e aplicação de conceitos científicos. Essa opção pode dificultar a promoção de discussões mais ampliadas do tema, já que aspectos de natureza política, econômica, social não são destacados.

Todavia, outras disciplinas apresentam caminhos que ampliam essa abordagem técnica, buscando, por exemplo, o suporte na complexidade para a análise da temática ambiental, caso da disciplina Física do Meio Ambiente (cursos $\mathrm{FLI}_{5}$ e $\mathrm{FLI}_{15}$ ). Com o auxílio da Física, essa disciplina propõe a compreensão da Terra como um sistema dinâmico e aberto, ao qual se associam características intrínsecas como a dinamicidade da Natureza, a irreversibilidade dos fenômenos naturais, as indeterminações e incertezas que acompanham as transformações do meio ambiente e as múltiplas e complexas interações estabelecidas entre os constituintes do sistema terrestre em seus diferentes níveis de organização. Sobre essa disciplina, o coordenador do curso $\mathrm{FLI}_{15}$ enfatiza que:

As disciplinas optativas são organizadas em blocos e um desses blocos a gente chama de 'bloco temático' que agrupa, justamente, as disciplinas que têm algum caráter um pouco mais interdisciplinar. Quer dizer, parte-se de um tema e não de uma área específica do conhecimento. Nesse bloco, a que eu mais destacaria é uma disciplina que se chama 'Física do meio ambiente' que é uma disciplina toda voltada para as questões ambientais. Aí nessa disciplina, em geral, se faz uma discussão dos conceitos da física e se estuda as diferentes temáticas ambientais. $\left[C_{15}, 2017\right]$. 
Em um enfoque próximo, a disciplina Física e Ciências da Vida objetiva construir a concepção de "[...] Natureza como um conjunto articulado de seres e acontecimentos interdependentes" (PPC FLI $4^{\prime}$ 2005, p. 51). Em um dos itens da sua ementa consta que serão utilizados os conhecimentos da Física e Biologia para "[...] descrever os processos e características do ambiente ou de seres vivos" (PPC $\mathrm{FLI}_{4^{\prime}}$ 2005, p. 51). Porém, para além da descrição, prioriza-se o desenvolvimento de posicionamentos críticos em relação às questões ambientais. Por isso, apresenta-se que a abordagem de "questões polêmicas"será valorizada, principalmente levando em consideração que "[...] mais do que fornecer certezas, é preciso criar espaço para as discussões e prover elementos para aprofundamento" (PPC FLI ${ }^{\prime}$ 2005, p. 51).

Essas disciplinas centram-se em uma abordagem que considera a Terra como uma organização sistêmica, ou seja, uma associação combinatória composta por elementos heterogêneos e inseparavelmente associados, cuja interação gera acontecimentos imprevisíveis. Esse sistema não é passível de previsões ou modelagens, já que o não determinismo, a imprevisibilidade, a irreversibilidade e a probabilidade são suas características intrínsecas. Com isso, essas disciplinas apresentam que a Física é uma área do conhecimento que oferece inúmeras possibilidades para a abordagem da temática ambiental sob o ponto de vista da complexidade (REIS; SILVA; FIGUEIREDO, 2015; WATANABE, 2012). Uma vez que esses futuros docentes estabelecem o contato com essa visão mais ampliada, serão incentivados a elaborarem suas atividades de ensino centradas em uma perspectiva complexa.

Um segundo agrupamento dentro dessa categoria reúne 21 disciplinas que tratam dos impactos ambientais causados pela tecnologia - desenvolvida a partir dos avanços da ciência - e valoriza espaços para refletir as possibilidades de minimizálos, a fim de formar profissionais comprometidos com um futuro ambientalmente sustentável (quadro 6).

Quadro 6 - Disciplinas agrupadas na subcategoria o impacto e a conservação ambiental

\begin{tabular}{|l|l|}
\hline \multicolumn{1}{|c|}{ Curso } & Disciplinas (Obrigatória) \\
\hline $\mathrm{FLI}_{1}$ & Eletromagnetismo I; Física Experimental I; Mecânica \\
\hline $\mathrm{FLI}_{2}$ & $\begin{array}{l}\text { Astronomia; Fund. da Eletricidade; Física Moderna e Contemporânea; História da Ciência e Tecnologia; Mecânica } \\
\text { dos Fluídos; Gravitação e Leis de Conservação; Introdução à Ciência Experimental }\end{array}$ \\
\hline $\mathrm{FLI}_{3}$ & Gravitação e leis de conservação \\
\hline $\mathrm{FLI}_{5}$ & Bases Conceituais da Energia \\
\hline $\mathrm{FLI}_{8}$ & Meio Ambiente e Desenvolvimento Sustentável; Poluição Ambiental \\
\hline $\mathrm{FLI}_{9}$ & Introdução à Química Ambiental \\
\hline $\mathrm{FLI}_{11}$ & Química Geral e Inorgânica \\
\hline $\mathrm{FLI}_{13}$ & Física e Sociedade - Ensino \\
\hline $\mathrm{Curso}$ & Disciplinas (Optativa ou Eletiva) \\
\hline $\mathrm{FLI}_{9}$ & Sociedade, Tecnologia e Meio Ambiente \\
\hline $\mathrm{FLI}_{14}$ & Fontes Alternativas de Energia; Física da Fala e Audição \\
\hline $\mathrm{FLI}_{15}$ & Física da poluição do ar \\
\hline
\end{tabular}

Fonte: elaborado pelos autores.

Dentre esses impactos ambientais, a poluição é o tema mais explorado. Como exemplo, ressaltamos a disciplina Física da poluição do ar (curso $\mathrm{FLI}_{15}$ ) que objetiva: "[...] Dar formação básica sobre a questão da poluição do ar, articulada aos demais 
problemas ambientais, bem como analisar sua vinculação com o modelo econômico e social presente em nossa sociedade". Essa disciplina chama a atenção pelo fato de propor uma reflexão do atual modelo de sociedade capitalista que tem contribuído significativamente com a intensificação dessa problemática.

Além de destacar o vínculo entre os modelos econômico e social e o problema da poluição, essa disciplina estabelece uma relação clara com a Física ao utilizar os conceitos dessa área do conhecimento para explorar o tema. Certamente, essa é uma discussão relevante, sendo esse um problema que assume grandes dimensões na atualidade. Nesse sentido, as causas desses impactos ambientais devem ser exploradas e problematizadas, como tentativa de contribuir com a formação de cidadãos que questionam o modelo de desenvolvimento econômico e social às custas do meio ambiente. Aproximando-se dessa perspectiva, em outras disciplinas fica clara a atenção para as principais causas dos impactos ambientais.

Nas ementas de três disciplinas (oferecidas pelos cursos $\mathrm{FLI}_{1}, \mathrm{FLI}_{2}$ e $\mathrm{FLI}_{9}$ ) está presente a consideração de que o desenvolvimento científico e tecnológico intensifica a degradação ambiental. Esse é o caso da disciplina História da Ciência e Tecnologia, que objetiva "[...] Analisar os impactos da ciência e da tecnologia nas várias etapas da história da civilização, avaliando no âmbito do desenvolvimento econômico-social o impacto deste no meio ambiente" (PPC FLI ${ }_{2}$ 2016, p. 73). Nesse caso, retomando os pressupostos do enfoque CTS, destacamos a relevância de evidenciar esses impactos causados pelo desenvolvimento científico e tecnológico. Dessa maneira, contribui-se para a desconstrução da ideia linear de que esse desenvolvimento conduza ao bemestar social, o que, por sua vez, incentiva uma postura crítica diante à C\&T que deixa de trazer apenas benefícios para a sociedade.

Outras seis disciplinas (oferecidas pelos cursos $\mathrm{FLI}_{1}, \mathrm{FLI}_{2}, \mathrm{FLI}_{5}$ e $\mathrm{FLI}_{14}$ ) exploram, especificamente, os impactos ambientais causados pelas usinas responsáveis pela produção de energia elétrica. A disciplina Bases Conceituais da Energia (curso $\mathrm{FLI}_{5}$ ), por exemplo, apresenta uma abordagem teórica que trata a definição do conceito energia e suas formas de conversão, o que viabiliza a abordagem do tema produção de energia elétrica e os seus impactos para o meio ambiente. Outro exemplo é a disciplina Fundamentos de Eletricidade cujo objetivo é o de promover a "[...] Discussão dos impactos que as diversas fontes de geração de energia elétrica têm sobre o meio ambiente" (PPC FLI 2 2016, p. 113).

Os debates relacionados com a produção de energia elétrica causam grande inquietação, principalmente quando o assunto se relaciona com os seus impactos irreversíveis no meio ambiente. De acordo com Silva e Carvalho (2006), a população dificilmente se preocupa com tais impactos, já que está submetida a um modelo de desenvolvimento econômico à custa da exploração dos recursos naturais. Por isso, os autores enfatizam a necessidade de que os impactos ambientais causados pela produção de energia elétrica sejam problematizados pelo ensino de Ciências.

Os autores supracitados destacam, ainda, as possibilidades oferecidas pela abordagem do tema no ensino de Física e enfatizam que, além de envolver conceitos específicos dessa área do conhecimento, essa temática "[...] possibilita ao professor de Física a oportunidade de enriquecer as aulas com a exploração de outros aspectos, além dos técnicos, tais como os sociais, ambientais e políticos" (SILVA; CARVALHO, 2006, p. 48). Esse tópico é, inclusive, destacado pelo coordenador do curso $\mathrm{FLI}_{14}$, ao 
discutir sobre as possibilidades que o curso de licenciatura em Física oferece para o tratamento da temática ambiental:

[...] se você vai falar de energia, qualquer tópico relacionado à energia passa por preservação do meio ambiente, problemas relacionados à poluição de vários níveis, seja por $\mathrm{CO}_{2}$, seja por impacto em água, seja por impacto de represamento em grandes açudes que possam inundar uma área grande, por poluição até nuclear. Você utilizar energia nuclear, o resíduo dos reatores que impacto isso possa ter... então, isso é de uma forma ou de outra discutido em determinadas disciplinas. $\left[{ }_{14^{\prime}}\right.$ 2017]

Assumimos um posicionamento favorável à presença desse assunto na formação inicial do professor de Física. Além de contribuir para ampliar a sua concepção do tema, esse docente terá condições de promover uma avaliação crítica junto aos seus alunos. Para tanto, enfatizamos que a inserção desse tema em um curso de licenciatura em Física deve ser avaliada com cautela a fim de evitar a promoção de análises simplistas e de discussões superficiais, impedindo a construção de críticas à promoção do desenvolvimento social a qualquer custo.

Por fim, identificamos a preocupação em discutir algumas ações para a preservação do meio ambiente em quatro disciplinas (cursos $\mathrm{FLI}_{1^{\prime}}, \mathrm{FLI}_{2^{\prime}} \mathrm{FLI}_{3}$ e $\mathrm{FLI}_{11}$ ). Esse é o caso da disciplina Meio Ambiente e Desenvolvimento Sustentável que objetiva "[...] aprofundar a análise sobre os fundamentos que sustentam a discussão sobre desenvolvimento e a preservação do meio ambiente" (PPC FLI ${ }_{3}$ 2015, p. 71). Sem dúvidas, essa é uma abordagem pertinente para os cursos de licenciatura em Física, uma forma de proporcionar ao professor em formação inicial oportunidades para refletir sobre possíveis ações capazes de minimizar esses impactos, sendo que muitas delas cabem ao espaço escolar.

Explorando as abordagens realizadas por esse conjunto de disciplinas, entendemos que os cursos de licenciatura em Física têm condições de suscitar uma série de debates que vão além da simples identificação dos tipos de impactos ambientais causados pelo desenvolvimento científico e tecnológico. Para tanto, é interessante valorizar uma visão ampliada da temática ambiental na medida em que as reflexões relacionadas aos aspectos políticos e econômicos são necessárias para a avaliação desses impactos e para a promoção de debates relacionados com o modelo de desenvolvimento econômico da sociedade contemporânea.

Por fim, para sistematizar as informações reunidas com esta pesquisa, construímos a figura 3, em que destacamos os elementos da temática ambiental privilegiados nos cursos de licenciatura em Física analisados, que podem ser reunidos em dois grupos: um relacionado às áreas da Educação e do Ensino e outro à área das Ciências Exatas e Naturais. Com isso, são apresentadas abordagens para a temática ambiental sob diferentes enfoques que, abordados em conjunto, oferecem ao licenciado em Física a oportunidade de uma reflexão mais ampla acerca da questão ambiental. 
Figura 3 - Abordagens para a temática ambiental nos cursos de licenciatura em Física oferecidos por IES públicas localizadas no estado de São Paulo, selecionadas para a investigação

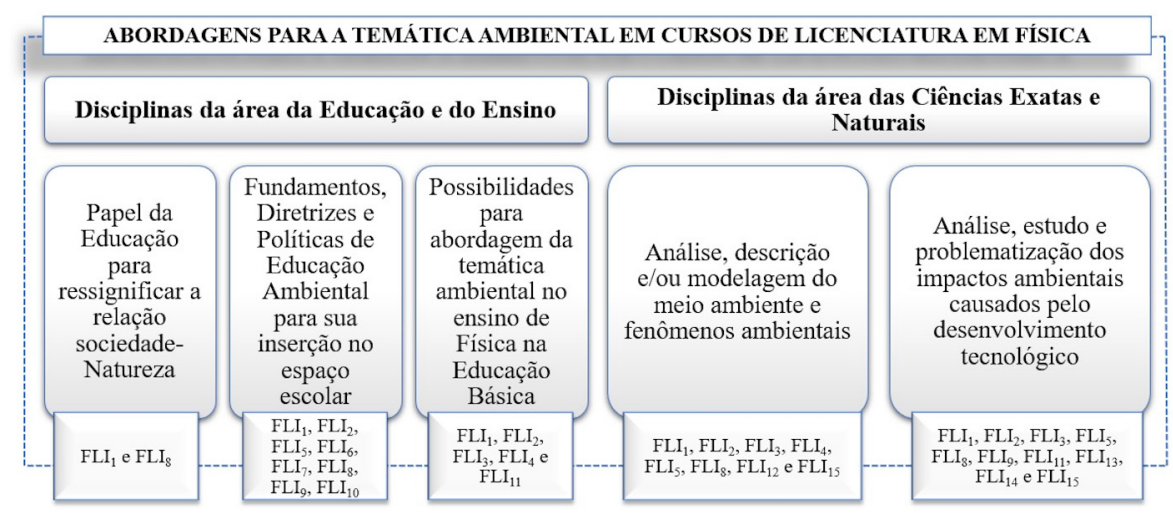

Fonte: elaborada pelos autores.

Assim, esse esquema sugere possibilidades para a inserção da temática ambiental na formação inicial do professor de Física.

\section{Considerações finais}

Nossas reflexões, escolhas e atitudes são, geralmente, respaldadas por um pensamento que separa, compartimentaliza e nos instrumentaliza para lidar com as diferentes situações cotidianas. Essa visão racionalista e disciplinar pode ser responsável por moldar em muitos professores uma identidade epistemológica que ajuda a explicar a sensação de que determinados problemas específicos não fazem parte do seu campo de atuação disciplinar. Como exemplo, podemos citar a concepção de que o ensino de Física e a temática ambiental sejam incompatíveis. Todavia, ao trazer resultados que apresentam possibilidades para a abordagem da temática ambiental nos currículos dos cursos de licenciatura em Física, esta pesquisa traz elementos que podem contribuir para a superação desse entendimento.

As disciplinas articuladas às áreas de Ensino e de Educação favorecem o pensar teórico-metodológico para a abordagem da temática ambiental no ensino de Física na educação básica. Buscam fomentar no professor em formação inicial a reflexão acerca das estratégias didáticas para ensinar Física através de temas ambientais, de forma a valorizar a problematização dessa temática por meio de elementos científicos, políticos, econômicos, sociais e culturais. Já as disciplinas vinculadas à área das Ciências Exatas e Naturais também viabilizam a presença do tema na formação do professor de Física de forma a despertar a sua 'consciência ambiental'. Alguns componentes curriculares valorizam uma abordagem que apresenta a Ciência como uma ferramenta capaz de promover a 'leitura técnica' da Natureza e dos seus fenômenos, enrijecendo as possibilidades para a construção de debates significativos sobre os problemas ambientais.

Assim, em resposta aos problemas que subsidiaram esta investigação, constatamos que os cursos de licenciatura em Física analisados abordam elementos da temática ambiental que viabilizam a compreensão do tema para além dos seus aspectos naturais, já que exploram sua interação com os meios social e econômico. Em determinados casos, podemos dizer que esta seria uma abordagem ampliada, na 
medida em que algumas disciplinas oferecem espaços para a construção de debates, reflexões e análises críticas acerca desse tema. Em outras situações, o tema recebe um tratamento de um ponto de vista mais técnico, ao passo que a Ciência é tida como um meio de controle e manipulação do meio ambiente e dos fenômenos naturais.

No que se refere às abordagens curriculares utilizadas para o tratamento da temática ambiental no processo de formação dos futuros professores de Física, concluímos que em 10 cursos os temas ambientais estão presentes nos currículos de forma pontual, através de disciplinas específicas. Nos demais cursos, identificamos aspectos da temática ambiental em um número maior de componentes curriculares, o que pode sugerir uma oportunidade para o tratamento do tema através de um enfoque holístico e interdisciplinar.

Enfatizamos que a abordagem da temática ambiental não deveria se restringir a uma ou duas disciplinas do currículo dos cursos de licenciatura em Física. Em um cenário ideal, seria relevante e pertinente que o tema estivesse articulado a diferentes disciplinas em diferentes momentos do curso, uma forma de propiciar abordagens diversificadas e sob diferentes perspectivas. No caso desta investigação, concluímos que essa abordagem diversificada é possível, uma vez que identificamos diferentes disciplinas que exploram diferentes elementos da temática ambiental nos cursos de licenciatura analisados. Todavia, ressaltamos que ainda temos um longo caminho a percorrer a fim de oferecer aos futuros professores de Física uma formação pautada em uma reflexão mais crítica acerca da temática ambiental, abordando uma dimensão política da realidade.

Como a ampliação deste estudo, sugerimos a realização de entrevistas com os professores que ministram essas disciplinas selecionadas nessa investigação. Com isso, seria possível analisar em maiores detalhes as abordagens teóricas e metodológicas utilizadas para o tratamento da temática ambiental nesses cursos de licenciatura em Física, os temas ambientais explorados e as articulações estabelecidas com a Física, dentre outros aspectos. Outra possibilidade seria a expansão deste estudo para outras universidades de outros estados brasileiros a fim de agregar novos dados e informações que auxiliariam a ampliar as conclusões apresentadas com este trabalho.

\section{Agradecimentos}

Os autores agradecem o apoio da Coordenação de Aperfeiçoamento de Pessoal de Nível Superior (CAPES), Código de Financiamento 001.

\section{Referências}

ALVES-MAZZOTTI, A. J.; GEWANDSZNAJDER, F. O método nas ciências sociais: pesquisa quantitativa e qualitativa. 2. ed. São Paulo: Pioneira, 2000.

BARDIN, L. Análise de conteúdo. São Paulo: Edições 70, 2016.

BRASIL. Ministério da Educação. e-MEC: cadastro nacional de cursos e instituições de educação superior. Brasília, MEC, 2017. Disponível em: http://emec.mec.gov.br/. Acesso em: 10 set. 2020.

CARVALHO, L. M. A temática ambiental e o processo educativo: dimensões e abordagens. In: CINQUETTI, H. S.; LOGAREZZI, A (org.). Consumo e resíduos: fundamentos para o trabalho educativo. São Carlos: EdUFSCAR, 2006, p. 19-41. 
CARVALHO, L. M; CAVALARI, R. M. F; SILVA. D. S. Ambientalização nas instituições de ensino superior: as teses e dissertações em educação ambiental desenvolvidas no Brasil. In: GUERRA, A. F. S. (org.). Ambientalização e sustentabilidade nas universidades: subsídios, reflexões e aprendizagens. Itajaí: Editora da Univali, 2015. Disponível em: https://bit.ly/2Qs7fzM. Acesso em: 5 ago. 2020.

DELIZOICOV, D.; ANGOTTI, J. A.; PERNAMBUCO, A. M. Ensino de ciências: fundamentos e métodos. 4. ed. São Paulo: Cortez, 2011.

FRASER, M. T. D.; GONDIM, S. M. G. Da fala do outro ao texto negociado: discussões sobre a entrevista na pesquisa qualitativa. Paidéia, Ribeirão Preto, v. 14, n. 28, p. 139-152, 2004. Disponível em: https://bit.ly/2M3cvel. Acesso em: 10 out. 2020.

GUIMARÃES, M. Por uma educação ambiental crítica na sociedade atual. Margens, Belém, v. 7, n. 9, p. 11-22, 2017. DOI: https://doi.org/gvjp.

HALMENSCHLAGER, K. R. Abordagem de temas em ciências da natureza no ensino médio: implicações na prática e na formação docente. 2014. 373 f. Tese (Doutorado em Educação Científica e Tecnológica) - Universidade Federal de Santa Catarina, Florianópolis, 2014. Disponível em: https://bit.ly/2Go00qz. Acesso em: 27 set. 2020.

OWENS, D. C.; SADLER, T. D.; ZEIDLER, D. L. Controversial issues in the science classroom. Kappan, Arlington, v. 99, n. 4, p. 45-49, 2018. DOI: https://doi.org/gvjm.

PEDRETTI, E. Environmental education and science education: ideology, hegemony, traditional knowledge, and alignment. Revista Brasileira de Pesquisa em Educação em Ciências, Belo Horizonte, v. 14, n. 2, p. 305-314, 2014. Disponível em: https://cutt.ly/iWHCUsX. Acesso em: 7 set. 2021.

PEDRETTI, E.; NAZIR, J. Currents in STSE education: mapping a complex field, 40 years on. Science Education, Hoboken, v. 95, n. 4, 601-626, 2011. DOI: https://doi.org/ct6wwg.

REIS, D. A.; SILVA, L. F.; FIGUEIREDO, N. As complexidades inerentes ao tema mudanças climáticas: desafios e perspectivas para o ensino de física. Ensaio, Belo Horizonte, v. 17, n. 3, p. 535-554, 2015. Disponível em: https://doi.org/gvjj. Acesso em 6 ago. 2020.

ROTH, W.; LEE, S. Scientific literacy as collective práxis. Public Understanding of Science, Trento, v. 11, p. 33-56, 2002. DOI: https://doi.org/10.1088/0963-6625/11/1/302.

SADLER, T. D.; MURAKAMI, C. D. Socio-scientific issues based teaching and learning: hydrofracturing as an illustrative context of a framework for implementation and research. Revista Brasileira de Pesquisa em Educação em Ciências, Belo Horizonte, v. 14, n. 2, p. 331-342, 2014. Disponível em: https://cutt.ly/XWqueK1. Acesso em: 10 ago. 2020.

SANTOS, W. L. P. O ensino de química para formar o cidadão: principais características e condições para a sua implantação na escola secundária brasileira. 1992. 232 f. Dissertação (Mestrado em Educação) - Faculdade de Educação, Universidade Estadual de Campinas, Campinas, 1992. Disponível em: https://bit.ly/2POlj9z. Acesso em: 15 ago. 2020.

SANTOS, W. L. P.; CARVALHO, L. M.; LEVINSON, R. A dimensão política da educação ambiental em investigações de revistas brasileiras de ensino de ciências. Revista Brasileira de Pesquisa em Educação em Ciências, Belo Horizonte, v. 14, n. 2, p. 199-213, 2014. Disponível em: https://bit. ly/2OezdOt. Acesso em: 5 set. 2020.

SILVA, L. F. A temática ambiental, o processo educativo e os temas controversos: implicações teóricas práticas para o ensino de física. 2007. 211 f. Tese (Doutorado em Educação Escolar) Universidade Estadual Paulista, Faculdade de Ciências e Letras, Araraquara, 2007. Disponível em: https://bit.ly/2RLm4h1. Acesso em: 17 set. 2020.

SILVA, L. F.; CARVALHO, L. M. Educação em ciências e temática ambiental: aproximações teóricometodológicas com a perspectiva educacional freireana. In: WATANABE, G. (org.). Educação científica freireana na escola. São Paulo: Livraria da Física, 2019. p. 149-168. 
SILVA, L. F.; CARVALHO, L. M. O ensino de física a partir de temas controversos: a produção de energia elétrica em larga escala. Interacções, Lisboa, v. 2, n. 4, p. 42-63, 2006. DOI: https://doi. org/10.25755/int.320.

STRIEDER, R. B. Abordagem CTS e ensino médio: espaços de articulação. 2008. 236 f. Dissertação (Mestrado em Ensino de Ciências) - Instituto de Física e Faculdade de Educação, Universidade de São Paulo, São Paulo, 2008. Disponível em: https://bit.ly/2OyQtx7. Acesso em: 10 ago. 2020.

SUND, P. Discerning selective traditions in science education: a qualitative study of teachers' responses to what is important in science teaching. Cultural Studies of Science Education, Dordrecht, v. 11, p. 387-409, 2016. DOI: https://doi.org/f3tpdf.

WATANABE, G. Aspectos da complexidade: contribuições da física para a compreensão do tema ambiental. 2012. 246 f. Tese (Doutorado em Ensino de Ciências) - Universidade de São Paulo, São Paulo, 2012. Disponível em: https://bit.ly/2zHWTET. Acesso em: 20 ago. 2020.

WATANABE-CARAMELLO, G.; STRIEDER, R. B.; GEHLEN, S. T. Desafios e possibilidades para a abordagem de temas ambientas em aulas de física. Revista Brasileira de Pesquisa em Educação em Ciências, Belo Horizonte, v. 12, n. 1, p. 205-222, 2012. Disponível em: https://cutt.ly/1WquJ1O. Acesso em: 28 ago. 2020. 